\section{PRESENCIAS NERUDIANAS EN EL PROCESO DE CREACIÓN Y EN ALGUNOS POEMAS DE MIGUEL HERNÁNDEZ}

\author{
CARMEN ALEMANY BAY
}

\section{Carmen Alemany Bay}

Profesora titular de literatura hispanoamericana de la Universidad de Alicante y directora del Centro de Estudios Iberoamericanos Mario Benedetti de la citada Universidad. Ha sido antóloga y editora de obras de Miguel Hernández, entre ellas, la Obra completa publicada por Espasa-Calpe. En literatura hispanoamericana destacan sus estudios sobre indigenismo y sobre poesía coloquial (Poética coloquial hispanoamericana), así como numerosos trabajos sobre poesía cubana, poesía mexicana (una edición sobre Jaime Sabines, artículos sobre José Emilio Pacheco), poesía uruguaya (artículos y un libro sobre Mario Benedetti). Otra línea de su investigación es las relaciones culturales entre España y América latina que se han materializado en su libro $E l$ meridiano intelectual en Hispanoamérica, en el número monográfico Relaciones entre la literatura española e hispanoamericana en el siglo $X X$ en la revista América sin nombre y en artículos sobre la relación entre autores españoles y latinoamericanos del siglo $\mathrm{XX}$.
Cualquier crítico que se aproxime a la obra de Pablo Neruda tendrá que hacer un alto en el camino para hablar de la profunda relación que éste mantuvo con el poeta oriolano $\mathrm{Mi}$ guel Hernández en los tiempos en que el chileno residió en Madrid, en la Casa de las Flores. Lo mismo tendrá que hacer, y quizá con más intensidad, quien quiera comprender el cambio poético y, en alguna medida político, que Miguel Hernández vivió en la capital de España a partir de su segundo viaje y hasta el comienzo de la guerra civil española. El cambio en su actitud poética tendrá tales dimensiones que incluso afectará - por otra parte, lógicamente- al proceso de creación previo a las versiones definitivas de sus poemas.

La presencia nerudiana en el quehacer literario hernandiano creemos que no sólo afectó a muchas de las composiciones clasificadas por la crítica como PSIII (es decir, los poemas sueltos que dentro de la obra hernandiana se situarían entre El rayo que no cesa y Viento del pueblo); sino que esa presencia es incluso más intensa y abarcadora: el Neruda de las primeras Residencias, o más bien el tono y el lenguaje nerudianos, tuvieron bastante que ver en algunas de las composiciones de El rayo.

Hagamos un breve resumen de la relación entre ambos autores. En marzo del 34, Miguel Hernández decide nuevamente viajar a $\mathrm{Ma-}$ drid con un libro ya publicado, Perito en lunas (1933), para trabajar con José María Cossío en la elaboración de la enciclopedia Los toros. Este segundo viaje será decisivo para su formación, o mejor, para su consolidación como poeta. Allí conocerá a muchos de los escritores del 27; pero sólo la amistad que ofrecerá al poeta chileno Pablo Neruda y a Vicente Aleixandre llegará a ser fructífera y sincera. Cuatro meses después de su estancia en Madrid, el 19 de julio, el oriolano conocerá a Pablo Neruda, quien residía aún en Barcelona pero realizaba constantes viajes a la capital de España. Finalmente, en febrero del $35^{1}$, el escritor de Veinte poemas... se trasladará de la ciudad condal a Madrid en donde vivirá una de las más plenas experiencias de su vida, como repitió en numerosas ocasiones. Muy cerca de la casa, la Casa de las Flores, viven Federico García Lorca, Rafael Alberti, también Manuel Altolaguirre, José Bergamín, Luis Cernuda y Vicente Aleixandre. Hernández, más pobre, vivía más lejos, en los arrabales de Madrid. El grupo se ve casi todos los días, se reúnen en los mismos bares, sobre todo en la cervecería de Correos, y allí comentan sus creaciones literarias. En el mes de abril poetas e intelectuales españoles homenajean al poeta chileno y entre ellos estará el ya casi inseparable Miguel Hernández, quien ha visto en Pablo Neruda al hombre amable y compasivo que no menosprecia-como sí hicieron muchos de los poetas de 27- los orígenes del oriolano y sus conocimientos intuitivos y autodidactas: "Yo lo conocí cuando llegaba de alpargatas y pantalón campesino de pana des-
1

La citada fecha es la comúnmente aceptada por la crítica nerudiana; sin embargo, en un reciente estudio, Julio Gálvez Barraza (Neruda y España, Providencia (Santiago de Chile), RIL, 2003 , p. 317) propone la de agosto de 1934 como verdadera fecha en la que Neruda se traslada definitivamente a Madrid.
Presencias nerudianas en el proceso de creación y en algunos poem de Miguel Hernández

CARMEN ALEMANY BAY 


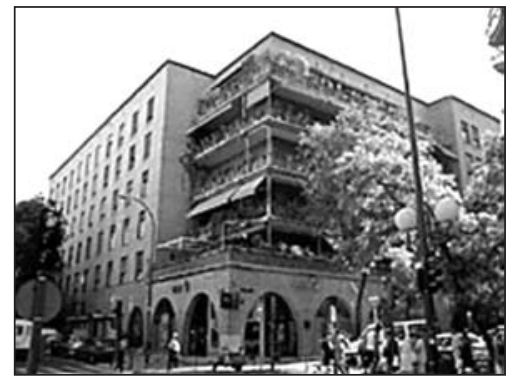

Casa de las flores en la actualidad.

2 Barcelona, Editorial Argos Vergara, 1979, p. 134.

Presencias nerudianas en el proceso de creación y en algunos poemas de Miguel Hernández

CARMEN ALEMANY BAY de sus tierras de Orihuela, en donde había sido pastor de cabras (...) Tenía una cara de terrón o de papa que se saca de entre las raíces y que conserva frescura subterránea. Vivía y escribía en mi casa. Mi poesía americana, con otros horizontes y llanuras, lo impresionó y lo fue cambiando", confesó el chileno en Confieso que be vivido ${ }^{2}$.

Miguel ha aprendido en estos meses madrileños -y cada vez más gracias a Nerudaque la poesía podía ser algo más que la referencia a la naturaleza y al catolicismo -como le había enseñado su amigo Ramón Sijé-, y que el verso podía tener libertades inusitadas que él nunca se había atrevido a experimentar. El poeta de Perito en lunas se acerca cada vez más a una visión social y comprometida que, si bien en algunos momentos se manifestó en ciernes, ahora es evidente: el oriolano ya ha entrado en la órbita nerudiana.

Por su parte, el poeta chileno, en la capital de España, dice sentirse como en su propia casa y, a iniciativa de Manuel Altolaguirre, funda una revista literaria con el título Caballo verde para la poesía. Allí, en su primer número, publica «Sobre una poesía sin pureza» y también Miguel Hernández dará a conocer dos de sus poemas, «Vecino de la muerte» y «Mi sangre es un camino», en los que imágenes surreales, muy al estilo nerudiano, se hacen patentes. Estos poemas, incluidos en PSIII, irán acompañados de otros totalmente nerudianos por su factura poética y porque están dedicados, uno al propio Neruda, «Oda entre sangre y vino a Pablo Neruda», y otro a su compañera de aquellos tiempos, Delia del Carril, en «Relación que dedico a mi amiga Delia», pero también otras composiciones de este grupo recibirán la influencia nerudiana.

PRESENCIAS NERUDIANAS EN LOS ESBOZOS Y EN LOS POEMAS ESCRITOS ENTRE EL RAYO QUE NO CESA Y VIENTO DEL PUEBLO

Este conjunto (PSIII) está compuesto por 16 poemas de la más diversa índole: algunos como «Mi sangre es un camino», «Sino sangriento», «Vecino de la muerte» o «Me sobra corazón» nos remiten a composiciones de $E l$ rayo porque hay una insistencia en lo trágico y en un fatalismo ligado en ocasiones a la pe- na amorosa. Otro subgrupo estaría integrado por los homenajes que dedica a poetas vivos como la oda a Pablo Neruda (y, ligado a ésta, el poema a Delia del Carril) y la dedicada a Vicente Aleixandre, o aquellos en los que homenajea a poetas muertos como la «Égloga» a Garcilaso de la Vega y «El ahogado del Tajo» en homenaje a Bécquer. Adelantamos que las composiciones con presencias nerudianas serán aquellas que tienen vinculaciones con $E l$ rayo $\mathrm{y}$, naturalmente, aquellas dedicadas al chileno y a su compañera.

Dos características comunes unen a todos los poemas de este grupo. La primera es la voluntad de cambio respecto a su poética anterior, o sea, un intento de entrar directamente en la poesía impura cuyas características definió Pablo Neruda en el primer número de $\mathrm{Ca}$ ballo verde para la poesía y, la otra, la que estará vinculada al proceso de creación en el que se vislumbran notables cambios respecto a la misma línea trazada en ciclos poéticos anteriores.

Una primera dificultad se presenta al estudiar el proceso de creación de este bloque. Y es que, al igual que en el ciclo anterior, el de El rayo que no cesa, es posible que muchos de los esbozos pertenecientes a los poemas en cuestión se perdiesen en Madrid; aunque ello no impide sin embargo tener una visión casi exacta de la producción de las composiciones. En el proceso de creación de estos poemas hay una diferencia de método tal como anunciábamos: en aquellos en los que hay un manifiesto cambio, por las influencias que hemos apuntado más arriba de Neruda y Aleixandre, Hernández ha construido unos textos previos que no remiten, aparentemente, al poema publicado; pero los centros temáticos son los mismos que en la versión definitiva. Incluso, en esta innovadora forma de creación de los bocetos es evidente un nuevo tipo de construcción versal que tendrá su plasmación en el verso libre que es el utilizado en muchas de las versiones definitivas. Claro ejemplo de lo que estamos diciendo lo encontramos en «Oda entre sangre y vino a Pablo Neruda» y en «Relación que dedico a mi amiga Delia», los poemas más pronerudianos de este grupo.

Respecto a «Oda entre sangre y vino a $\mathrm{Pa}$ blo Neruda», que el poeta oriolano escribió probablemente a mediados del año 35, Hernández redactó un esbozo previo a la versión definitiva en el que el contenido y la cons- 
trucción de las imágenes nos remiten al poema en cuestión. Si en ciclos anteriores, las primeras concepciones del poema remitían a frases e incluso a versos que reproducía en la versión definitiva, en esta ocasión, el esbozo se convierte en un ensayo, en frases repletas de imágenes que no tienen precedentes en esbozos previos a la versión definitiva de otros poemas: un nuevo vocabulario, sin olvidar el ya creado en su poética anterior, emerge en este boceto y en el poema. También en esta ocasión, Hernández intenta imitar, como en las composiciones dedicadas a Garcilaso, a Bécquer y a Aleixandre, el estilo y el tono poético de los escritores homenajeados.

Meses después de la composición de este poema, en los folletones del periódico madrileño El Sol, Hernández escribirá una crítica sobre Residencia en la tierra donde efusivamente exponía que:

La voz de Pablo Neruda es un clamor oceánico que no se puede limitar, es un lamento demasiado primitivo y grande, que no admite presidios retóricos. Estamos escuchando la voz virgen del hombre que arrastra por la tierra sus instintos de león; es un rugi$\mathrm{do}, \mathrm{y}$ a los rugidos nadie intenta ponerles trabas. Busca en otros la sujeción a lo que se llama oficialmente la forma. En él se dan las cosas como en la Biblia y el mar: libre y grandiosamente. Canta como un profeta desventurado ${ }^{3}$.

Precisamente ese «clamor oceánico» es el que intenta transmitir Hernández en su esbozo y, posteriormente, en el poema. Si en la versión definitiva el poeta intenta hacer un retrato de Neruda a través del primer poema de $E l$ hondero entusiasta, "Hago girar mis brazos como dos aspas locas», y del «Estatuto del vino» de Residencia en la tierra; en el esbozo aparece difuminada esta influencia y comienza la descripción de Neruda con unas frases que nos remiten al primer cuarteto del soneto 3 de El rayo que no cesa. Veamos ambos textos. En el esbozo a la «Oda» reza lo siguiente:

un sentimiento, un tiburón muy dulce- encima de los ojos tus dos velludas guadañas enfurecidas- repugnantes espumas, aguas de maldición caen de mis ojosmaldecidas espumas maldicientes (...) tu boca con sus cuatro guadañas de hacer daño y besar el barro y su ternura de pezuña que acaba de nacer y no ha pisado el mundo todavía- ${ }^{4}$
Y en el soneto del Rayo dice así:

Guiando un tribunal de tiburones, como con dos guadañas eclipsadas, con dos cejas tiznadas y cortadas de tiznar y cortar los corazones (495),

también en el soneto 24 de El rayo encontraremos las mismas resonancias:

que un dulce tiburón, que una manada

de inofensivos cuernos recentales,

habitándome días, meses, años (507).

Adelantamos que en muchos de los poemas de El rayo la presencia nerudiana es un hecho; pero el esbozo del poema, específicamente en las líneas transcritas anteriormente, nos remite también a algunos versos del primer poema de la segunda Residencia en la tierra, «Un día sobresale»:

Peces en el sonido, lentos, agudos, húmedos, arqueadas masas de oro con gotas en la cola, tiburones de escama y espuma temblorosa, salmones azulados de congelados ojos ${ }^{5}$

Y el comienzo del esbozo «Y pájaros de todas las especies y guitarras de todas las edades- y órganos de todos los tamaños- cañaveral de flautas añadidas- pájaros con las alas entornadas» vuelven a remitirnos a algunos versos de «Sabor», poema de la primera Residencia:

En mi interior de guitarra hay un aire viejo

(...)

un pájaro de rigor cuida mi cabeza:

un ángel invariable vive en mi espada (19)

Sigue la descripción de Neruda en el esbozo, pero ahora utilizando un vocabulario más cercano al del poeta chileno que se entrecruza con el suyo: «unos dientes cansados de comer saliva solamente- el corazón de un canario- la lengua de un verderol». La presencia del término «corazón», $\tan$ frecuente en este boceto y por otra parte tan nerudiano, penetra en el esbozo donde se repite en varias ocasiones: «mi corazón, un sapo atribulado- la calavera una nuez, cárcel de mi corazón- mi corazón enjaulado- (...) fuerte corazón». Estamos ante un esbozo donde Hernández ha intentado hacer un retrato del poeta con elementos her-

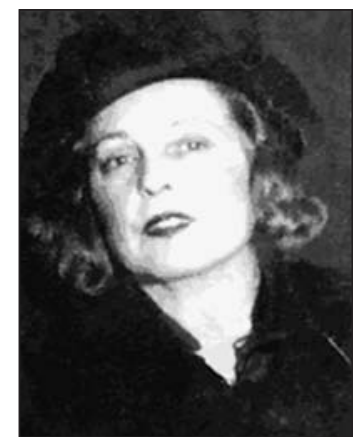

Delia del Carril.

3

Miguel Hernández, «Residencia en la tierra. Poesía 1925-1935. Pablo Neruda», en Teatro, prosas, correspondencia (edición crítica de Agustín Sánchez Vidal, José Carlos Rovira y Carmen Alemany), tomo II, Madrid, Espasa- Calpe, 1992, p. 2152.

4

Miguel Hernández, Poesía ledición crítica de Agustín Sánchez Vidal, José Carlos Rovira y Carmen Alemany), tomo I, Madrid, Espasa- Calpe, 1992, p. 997. En adelante citaremos por esta edición los esbozos y los poemas hernandianos $y$ anotaremos en el texto principal, entre paréntesis, el número de página.

\section{5}

Pablo Neruda, Residencia en la tierra, Buenos Aires, Losada, 1971, p. 73. En adelante citaremos por esta edición los poemas de Neruda y anotaremos en el texto principal, entre paréntesis, el número de página.

Presencias nerudianas en el proceso de creación y en algunos poemas de Miguel Hernández

CARMEN ALEMANY BAY 


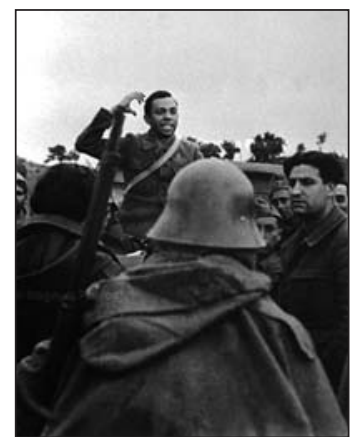

Miguel Hernández en el frente.

6

Marie Chevallier, Los temas poéticos de Miguel Hernández, Madrid, Siglo XXI, 1978, pp. 275276. En este mismo libro se dedica un amplio estudio (pp. 264-276) a las relaciones intertextuales entre dos poemas de Neruda, "Hago girar mis brazos como dos aspas locas» y «Estatuto del vino", y la oda que Hernández dedica a Neruda.

Presencias nerudianas en el proceso de creación y en algunos poemas de Miguel Hernández

CARMEN ALEMANY BAY nandianos pero con una permanente lucha por introducir vocabulario nerudiano y referencias a sus poemas. Otras frases de este texto, como «vendrán pronto los perros a comerse los cadáveres cuando salen los perros a remover basura», nos recuerdan al lenguaje de las Residencias y, al mismo tiempo, enlazan con otro poema de esta serie hernandiana, con «Vecino de la muerte»:

Prefiero que me coman los lobos y los perros, que mis huesos actúen como estacas

para atar cerdos o picar espartos (529)

A diferencia de lo que ocurría en el proceso de creación de Perito en lunas, de los poemas escritos entre Perito y El rayo, e incluso en algunos de El rayo, los esbozos no le sirven para elaborar directamente los poemas; ahora los esbozos, como anunciábamos más arriba, son intuiciones que después aparecen bastante trasmutadas en la versión definitiva en la que sólo se recuperarán casi íntegramente algunas palabras del texto previo: «tu boca con sus cuatro guadañas de hacer daño y besar el barro y su ternura de pezuña que acaba de nacer y no ha pisado el mundo todavía», aparecerán de la siguiente forma en la versión definitiva del poema: «la bipartida huella de una boca, / la más dulce pezuña que ha pisado» (vv. 97-98, p. 524).

En la versión definitiva, donde Hernández teje el texto partiendo directamente de la poesía de Neruda, Marie Chevalier ha señalado:

En el retrato de Neruda que constituye la oda que le es dedicada, retrato ejecutado con formas poéticas precisas, hasta el mimetismo del vocabulario, todo ello tomado de Neruda, Miguel Hernández expresa su admiración apasionada, restituyendo el rostro de su amigo a través de su propia mirada interior ${ }^{6}$.

La misma liberación del verso que aparecía en el poema dedicado a Neruda, y otros de este ciclo, se repite en «Relación que dedico a mi amiga Delia». En esta ocasión el poeta, utilizando elementos surrealistas, nos describe la personalidad de la compañera de Neruda y su proceso de creación es un caso bastante significativo en la poética del oriolano. En la primera concepción del poema, un esbozo muy breve, se hace una descripción de encuentros y desencuentros de fuerzas cosmológicas que describen, simbólicamente según nuestra opi- nión, las relaciones entre Pablo y Delia. En este esbozo, como será habitual en este momento de su producción, el poeta nuevamente ha creado una primera idea que se aleja del resultado definitivo:

tragársela quisiera, devorarla ambiciona- un planeta de amor y otro de guerra chocan y se entrelazan, se rechazan, se buscan y se abrazan el mar de sangre y su mujer de arcilla- la muerte chocante ante la (...) se mece, se detiene, se arrodilla como a veces el mar ante la tierra (998)

Después de la creación de este primer esbozo redacta otro en el que, tras un breve boceto, desarrolla el poema con variantes. Este proceso de creación que parte de un boceto y a continuación elabora el poema con notables variantes, fue un modo de escribir muy habitual durante su primer ciclo (el de Perito), y con alguna presencia en el segundo (el que desembocará en El rayo que no cesa). La característica de esta creación, ya próxima al poema definitivo, es que en el esbozo previo, tras la primera frase, «tienes las (manos) blancas de tratar con la luna y los ojos azules de penar en el mar» (que podría tener alguna relación con el primer esbozo), apunta que lo que está escribiendo y lo que va a escribir es para ese poema en concreto, "para el poema Delia", actuando esta frase como un mecanismo de memoria que será utilizado, de otra forma, en el Cancionero y romancero de ausencias. A continuación escribe: «tu cabeza de espiga cubierta de abundancia se atiene a sus lados con un desmayo de oro cansado de brillar y se yergue emitiendo cereales relámpagos», lo que casi de forma idéntica aparecerá en los versos del 12 al 14:

Tu cabeza de espiga se vence hacia los lados con un desmayo de oro cansado de abundar y se yergue relampagueando trigo por todas partes (525)

Nótese que palabras tan nerudianas como «cereales relámpagos» has sido sustituidas por «relampagueando trigo», intentando mitigar la excesiva presencia. A continuación, el esbozo contiene frases como «tu ternura de agua que pasa entre unos márgenes de zarzas y de toros» que en la versión definitiva comprenderán los versos del 9 al 11, lo que lleva implícito un cambio de orden en la versión definitiva: 
tu ternura es capaz de abrazar a los cardos y en ella veo un agua que pasa y no se altera entre orillas ariscas de zarza y tauromaquia

En la segunda parte del poema, Hernández escribe un primer verso, «No encontraréis a Delia sino muy repartida como el pan de los pobres» que nos trae recuerdos de otro verso de «Josie Bliss» en el que Neruda decía «yo existo en ese día repartido» (136), al igual que Delia; pero también el poema ha sido relacionado por la crítica con «La unión libre» de André Breton por su asimilación de las técnicas surrealistas que hasta ahora no habían estado presentes en la poética hernandiana.

La presencia nerudiana en las versiones definitivas de «Oda entre sangre y vino a Pablo Neruda»y «Relación que dedico a mi amiga Delia» está por doquier. No podía ser de otra forma. Pero quizá lo más interesante sea que en los esbozos se encuentren referencias a otras composiciones de este bloque; lo que nos lleva a insistir en la presencia nerudiana en muchos de los poemas que conforman este conjunto poético.

Llegados a este punto debemos señalar que si bien el poeta oriolano dio un giro significativo en lo político gracias a la influencia, entre otros, de Pablo Neruda; en lo poético, la lectura de Veinte poemas de amor, de El hondero entusiasta y, fundamentalmente, de las dos primeras Residencia en la tierra, publicadas conjuntamente por la editorial española Cruz $y$ raya en septiembre del 35 -sin olvidar la fructífera relación que el oriolano y el chileno mantuvieron-, dieron como resultado que Miguel Hernández cambiase su concepción de lo poético. Sin embargo, ese mimetismo nunca logró borrar la autenticidad poética del escritor español. Lo que Hernández adoptó de la poesía de Pablo Neruda fue la utilización del verso libre mucho menos variado que el nerudiano ya que el suyo, por su práctica poética anterior muy acostumbrada a estrofas cerradas, suele articularse en cadencias que reproducen endecasílabos y heptasílabos (silvas) e incluso combinaciones de 5 y 7 que parecen seguidillas insertadas entre versos libres. Una liberación versal que irá acompañada de la incorporación de términos hasta esos momentos inéditos en el caudal poético hernandiano, o bien utilizados pero con otras significaciones (amapolas, mar, vino, caracolas, corazón, etc.); palabras que le ayudarán también a liberarse de una materia verbal que tiende cada vez más al apasionamiento. Esa pasión articulada en versos surrealistas (de un surrealismo poco dogmático) y oníricos que encontramos en las Residencias dotarán a la poesía de Hernández de una potencia y violencia verbales inusitadas. Las imágenes, acompañadas por paralelismos y por un uso continuado de gerundios, se tornarán casi irracionales, máxime si las comparamos con la producción hernandiana anterior.

Hernández vio en el hombre Neruda al protector, al maestro y, en sus Residencias, encontró la misma pena, desgarramiento y dolor con los que él estaba alimentando su poesía: las fuerzas siniestras de la muerte, la tragedia de la condición humana o la insuficiencia del amor. Este cierto regusto por lo existencial convertirá a Neruda en un poeta más próximo y de una elementalidad que hermana con la suya a pesar de que la materialidad con que Neruda poetiza objetos menores y cercanos, o la voz casi profética de las dos Residencias están, sin embargo, prácticamente ausentes en la poética hernandiana de aquel tiempo.

La sombra de Neruda estará también presente en los poemas que publicó en Caballo verde para la poesía, «Vecino de la muerte» y «Mi sangre es un camino», como decíamos más arriba; asimismo, los versos desatados, telúricos y crispados muy al estilo nerudiano que conforman estos poemas seguirán en otros como «Alba de hachas», «Me sobra corazón» $\mathrm{y}$ «Sino sangriento».

Todo este corpus textual de PSIII aparece encabezado por el poema «Elegía», dedicado a la que fue novia de Ramón Sijé y escrito después de la muerte de éste. En una carta dirigida a Carlos Fenoll, hermano de la novia de Sijé, fechada en Madrid en febrero de 1936, Hernández le dice lo siguiente: «Siento mucho haberla hecho después de estar publicado mi libro (El rayo que no cesa): me hubiera gustado incluirla en él también. Pero creo que pronto la publicaré en cualquier revista» ${ }^{7}$. El poema está construido, al igual que la elegía a Sijé, en tercetos encadenados y es prácticamente una continuación de ésta, ya que el poeta sigue utilizando el mismo tipo de vocabulario. Con todos estos precedentes de similitud entre ambas elegías no cabe más que volver a hablar de la presencia nerudiana.

En la biografía del poeta oriolano realizada por Agustín Sánchez Vidal, Miguel Her-

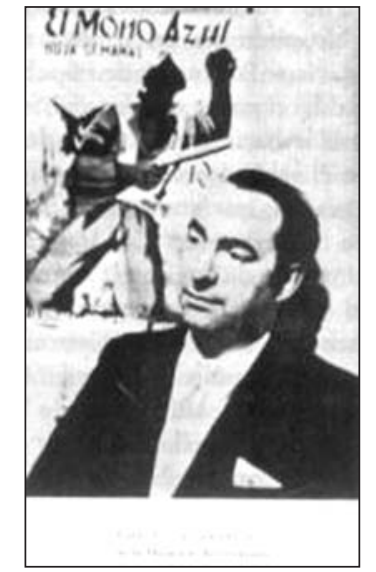

Neruda en Madrid iniciada la guerra.

7

Miguel Hernández, Teatro, prosas, correspondencia, op. cit., pp. 2368-2369.

Presencias nerudianas en el proceso de creación y en algunos poemas de Miguel Hernández

CARMEN ALEMANY BAY 


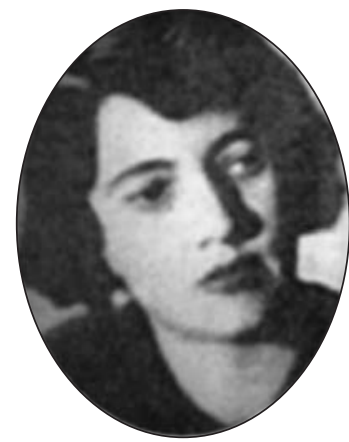

Maria Antonieta Hagenaar.

8

Vid., Agustín Sánchez Vidal, Miguel Hernández, desamordaza do y regresado, Barcelona, Planeta, 1992, pp. 195-197.

\section{9}

Copiamos algunas opiniones de los críticos sobre este tema que aparecen recogidas en el artículo de Stephen Hart, «Miguel Hernández y Pablo Neruda: dos modos de influir» (Revista de crítica literaria latinoamericana, Lima, 26, 2do. semestre de 1987, pp. 115-122): «Existe en la crítica contemporánea sobre estas dos figuras centrales de la lírica moderna una tendencia a exagerar el influjo que Neruda ejerció sobre la obra miguelhernandiana. Manuel Durán, por su parte, afirma que «es bien sabido cuán hondo fue el influjo de Neruda sobre Hernández», como si fuese una verdad indiscutible. Jacinto Luis Guereña califica a la amistad entre los dos poetas "como maestro y discípulo». Emir Rodríguez Monegal puntualiza que «Neruda mimaba a Hernández como si fuera su propio hijo». Este énfasis en la crítica tiende a dar a Hernández el rol de mero imitador del estilo y poética nerudianos, lo que es una exageración. Como veremos Hernández fue impresionado por la poesía del poeta chileno, pero no la imitó a ciegas. Residencia en la tierra (1933) le dio al poeta oriolano la iniciativa a descubrir su propia voz poética y a seguir un curso independiente $y$ auténticamente personal» (pp. 115-116). En cambio, para Cano Ballesta (en La poesía de Miguel Hernández, Madrid, Gredos, 1971, 2ª edición), sí hay una influencia decisiva de Neru-

Presencias nerudianas en el proceso de creación y en algunos poemas de Miguel Hernández

CARMEN ALEMANY BAY nández desamordazado y regresado, el citado crítico se recrea en la elegía de Sijé y comenta -como ya había hecho en alguna otra ocasiónla influencia de Neruda en el poema y sobre todo en la relación existente entre ésta y «El desenterrado» de la segunda Residencia e, incluso, la relación de la «Elegía» con la oda a Pablo Neruda: las caracolas, las amapolas, el corazón y los órganos tan nerudianos se enredan entre los versos hernandianos ${ }^{8}$. Por la similitud entre ambas elegías -como mencionábamos antes- no es gratuito pensar que lo nerudiano también emerge en la «Elegía (a la panadera)» y sólo basta acudir a esos versos para constatarlo. Nuevamente en el proceso de creación de esta elegía, del que sí existe un esbozo previo, se exhiben amplias muestras de la influencia nerudiana. El boceto aparece, como ha hecho hasta esos momentos, construido con frases que separa entre guiones y, al igual que en los esbozos de los ciclos anteriores, ha escrito frases que pasan a la versión definitiva. En algunos casos aparecen ideas que ha tachado y que se repiten casi íntegramente en el poema definitivo, lo que nos ratifica en la hipótesis que alguna vez hemos afirmado de que Hernández escribe la primera idea del poema $y$, con ésta delante, va construyendo los versos. El poeta escribe en el esbozo a la «Elegía (a la panadera)» frases que vagan entre el nerudismo y el hernandismo:

él me ayudaba a paginar mis flores, él te ayudaba a apacentar tus pasiones un corazón de relámpagos y afanes (995)

que corresponde en la versión definitiva a los vv. 43-45:

Corazón de relámpagos y afanes,

paginaba los libros de tus rosas,

apacentaba el hato de tus panes (516)

da en la producción de los poemas de estos años: «Poemas hernandianos de este período son una proyección directa proclamada por el maestro Neruda. Precisamente tales enumeraciones de objetos inertes y tal ampliación del material metafórico y poético sobreabunda en "Vecino de la muerte» publicado en el primer
O bien, como escribe en el esbozo, «levántate: te esperan tus zapatos- dormidos y vacíos bajo el lecho y tu llanto en sus retratos» que se convierte en:

Levántate: te esperan tus zapatos

junto a los suyos muertos en tu cama,

y la lluviosa pena en sus retratos

(vv. 64-66, p. 517)

También otras frases como «y está mi alma ronca de nombrarte- abandonada por el pan y el vino» que tienen claro sabor nerudiano.

Los ejemplos expuestos hasta esta estos momentos, creo, dejan clara evidencia de que Pablo Neruda contagió la poesía de Hernández y le dio una libertad que el oriolano venía pidiendo a gritos. Pero una preocupación crítica resurge de lo dicho en los últimos párrafos: si la «Elegía» de Sijé incluida en El rayo que no cesa, a pesar de que no estaba previsto, tiene presencias nerudianas ¿cabría la posibilidad de plantearse que la órbita nerudiana también hubiese hecho mella en El rayo? Creo que sí.

\section{EL NERUDA DE EL RAYO QUE NO CESA}

La crítica hernandiana ha insistido en la amistad entre ambos poetas y en la transmutación que vivió el joven Miguel Hernández por su relación con Pablo Neruda; lo que le llevó a cambiar el contenido, y también el tono, de sus poemas aunque siempre siguió manteniendo intacta su raíz campesina9. Han insistido también en que la presencia nerudiana se concentra en los poemas que el oriolano escribió entre El rayo que no cesa y Viento del pueblo. Sin embargo, pocas veces la crítica hernandiana se ha planteado la vinculación entre El rayo y la influencia de Neruda, obviando que parte de este poemario fue escrito en Madrid y ante la presencia del autor de $R e-$ sidencia en la tierra.

Hagamos un poco de historia sobre este libro. El rayo que no cesa, poemario dedicado a Josefina Manresa, quien se convertirá en su esposa en el año 37, fue publicado por Manuel Altolaguirre en enero de 1936 en Madrid, dentro de la colección Héroe. Fue redactado entre 1934 y 1935, años en los que Hernández, como hemos apuntado, está en Madrid y realiza eventuales viajes a Orihuela. 
El rayo tiene unas características bastante peculiares. Es un libro perfectamente organizado y elaborado: está compuesto por un poema, «Un carnívoro cuchillo», escrito en redondillas de rima alterna; le siguen trece sonetos $\mathrm{y}$, a continuación, el poema quince, «Me llamo barro», escrito en silva polimétrica, que va seguido de otros trece sonetos, la «Elegía» a Sijé, escrita en tercetos encadenados y un «Soneto final» que cierra el libro. La otra peculiaridad es que parte de los sonetos allí integrados provienen de otros proyectos de libro: El silbo vulnerado, un poemario que nunca llegó a publicar el autor como tal y que años después fue editado junto con El rayo por José María de Cossío. En los poemas de El silbo se manifiesta una clara ascendencia católica que nos remite a la influencia de Ramón Sijé y, por el título, al Cántico espiritual de San Juan de la Cruz; algunos de estos sonetos pasarán, con variantes, a otro proyecto de libro, Imagen de tu buella, en los que aún se percibe la mencionada influencia del Cántico espiritual y también del Cantar de los cantares. Por tanto, algunos de los sonetos de El rayo provienen directamente de El silbo, otros nacieron de El silbo y se adaptaron con variantes a Imagen de tu buella y pasaron finalmente a formar parte de El rayo. También los hay que fueron creados para Imagen de tu buella y pasaron, nuevamente con variantes, a El ra$y o^{10}$. En cualquier caso, quedan todavía muchas composiciones que no tuvieron su origen en estos libros iniciales como «Un carnívoro cuchillo» o «Me llamo barro» y también la «Elegía» a Sijé, así como muchos sonetos en los que, al igual que en los poemas citados anteriormente, creemos hay una clara presencia de elementos nerudianos. Nos estamos refiriendo a «¿No cesará este rayo...??», «Guiando un tribunal», «Por tu pie, la blancura más bailable», «Si la sangre también», «El toro sabe al fin», «No me conformo», « ¿Recuerdas aquel cuello...», «Vierto la red», "Como el toro», «Fatiga tanto andar», «Al derramar tu voz», «Por una senda», «Lluviosos ojos» o «La muerte». Esa presencia nerudiana se concreta, al igual que en los poemas escritos entre El rayo y Viento del pueblo (PSIII), en la incorporación de vocabulario propio del poeta chile- no, de imágenes surreales que sirven para acentuar la pena amorosa y el presentimiento de un destino trágico (algo así tan nerudiano como la desintegración del mundo que podemos leer en las dos primeras Residencias). Pero hay una notable diferencia en la forma respecto a la presencia nerudiana en los poemas de PSIII, y es que aquí Hernández está entregado a la estructura del soneto, estrofa cerrada de la que poco tardará en liberarse.

Desde esta óptica, los poemas y sonetos citados contrastan con los sonetos del resto del libro en los que aún se mantiene la antigua influencia de Ramón Sijé, quien no ve con buenos ojos el acercamiento de Hernández al mundo literario, por añadidura político, de los Neruda, Aleixandre, Alberti y otros poetas que influían, negativamente según Sijé, en su vida y en su obra. Lo comedido de los sonetos que provienen de antiguos proyectos de libro contrasta con esos otros en los que el vocabulario nerudiano (buracanes, raíces irritadas, peces embotellados, tiburones, guadañas, redes, ovas, aguas, surcos, amapolas, crines, arenas, desierto, agujeros, lluviosas soledades o volcánicos bramidos), se entremezcla con el hernandiano y nos permite ya entrever otra realidad en la poética de Hernández. Y es que en El rayo que no cesa se denota ya la transición de la experiencia humana y la maduración ideológica del poeta oriolano de la mano de Pablo Neruda: Miguel Hernández demuestra en estos poemas liberados ya de silbos y de imágenes que habla el poeta, pero sobre todo ha empezado a hablar el hombre, dotando a sus versos de una concepción lejana de la artificiosidad que embargaba su poesía anterior e incluso muchos de los sonetos de $E l$ rayo.

En la capital madrileña, Miguel Hernández intuyó que su poesía estaba necesitada de nuevos lances, necesitaba liberarse de la rémora oriolana y sijeniana y se encontró en el camino a Pablo Neruda, quien con su magisterio y amistad le hizo vislumbrar nuevos horizontes que quedarán para siempre impresos en la poética hernandiana. En aquellos años madrileños, Neruda, y otros poetas como Vicente Aleixandre, fueron para Hernández la tradición literaria.

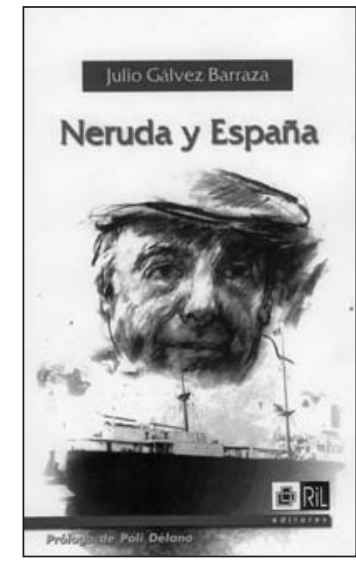

10

Para ver los poemas que pertenecen a proyectos de libros anteriores a El rayo, véase Migue Hernández, Obra completa Poesía, I, p. 985
Presencias nerudianas en el proceso de Miguel Hernández

CARMEN ALEMANY BAY 